\title{
PRÁTICAS COLABORATIVAS PARA INTERVENÇÃO EM GRUPO COM ADOLESCENTES E PROFISSIONAIS DE SAÚDE SOBRE SEXUALIDADE
}

\author{
COLLABORATIVE PRACTICES FOR GROUP INTERVENTION WITH \\ ADOLESCENTS AND HEALTH PROFESSIONALS ABOUT SEXUALITY
}

\section{DOMITILA KAWAKAMI GONZAGA $^{1} 2$}

\section{CARLA GUANAES- LORENZI ${ }^{2}$}

${ }^{1}$ Programa de Pós-Graduação em Psicologia da Faculdade de Filosofia, Ciências e Letras de Ribeirão Preto (FFCLRPUSP), Ribeirão Preto/SP,

Brasil

${ }^{2}$ Programa de Pós-Graduação em Psicologia da Faculdade de Filosofia, Ciências e Letras de Ribeirão Preto (FFCLRPUSP), Ribeirão Preto/SP, Brasil e Departamento de Psicologia da Faculdade de Filosofia, Ciências e Letras de Ribeirão Preto (FFCLRP-USP), Ribeirão Preto/SP, Brasil
RESUMO: 0 relato experiência de intervenção colaborativa como possibilidade para construção de discursos alternativos sobre adolescentes e sexualidades constitui 0 objetivo do presente artigo. Trata-se de pesquisa-ação colaborativa envolvendo: passos de construção da intervenção; organização e desenvolvimento do grupo; entrevistas de avaliação. 0 processo de produção de sentidos foi registrado por notas de campo, áudio do grupo e entrevistas, sensibilizado pelas Práticas Colaborativas. Envolveu oito adolescentes, nove profissionais e pesquisadoras, em ambos planejamento e desenvolvimento. 0 grupo propriamente dito compreendeu sete encontros e seguiu as temáticas eleitas conjuntamente: gênero e sexualidade; puberdade; métodos contraceptivos; sexualidade na adolescência; parentalidade/maternidade na adolescência; álcool e outras drogas; escolhas e repercussões. Narramos relação como pesquisadoras participantes e destacamos a participação de três adolescentes no grupo. Evidenciamos 0 agir colaborativo e a singularidade das pessoas, evitando rotulações, portanto a potência das práticas colaborativas para atitudes democráticas na construção e manejo do grupo, favorecendo conversas sobre sexualidade na adolescência.

PALAVRAS-CHAVE: Práticas colaborativas; Processos grupais; Adolescentes; Sexualidade.
ABSTRACT: The objective of this paper is to report the experience of collaborative intervention as a possibility for construction of alternative discourses about adolescents and sexualities. It is a collaborative action-research involving: steps of construction of the intervention; group organization and development; evaluation interviews. The process of meaning making was recorded by field notes, group audio and interviews, sensitized by Collaborative Practices. It involved eight teenagers, nine professionals and researchers, in both planning and development. The group itself comprised seven meetings and followed the chosen together themes: gender and sexuality; puberty; contraceptive methods; adolescent sexuality; parenting / maternity in adolescence; alcohol and other drugs; choices and repercussions. We narrate relationship as participating researchers and highlight the participation of three adolescents in the group. We highlight the collaborative action and the singularity of people, avoiding labeling, therefore the power of collaborative practices for democratic attitudes in group construction and management, favoring conversations about sexuality in adolescence.

KEYWORDS: Collaborative Practices; Group processes; Adolescents; Sexuality.

\section{INTRODUÇÃo}

Neste artigo buscamos contribuir com o desenvolvimento de conhecimen-

Recebido em: 31/08/2019 Aprovado em: 10/10/2019 tos sobre o emprego de práticas profissionais no campo da sexualidade e saúde reprodutiva de adolescentes, considerando o processo de colaboração entre 
profissionais e adolescentes. Sustentamos o entendimento de que trabalhar com temáticas envolvendo sexualidade de adolescentes apresenta uma série de desafios, dentre os quais destacamos particularidades da adolescência como etapa do desenvolvimento, dificuldades das/os profissionais dialogarem sobre temas considerados tabus e a adoção de metodologias participativas de trabalho, capazes de engajar as pessoas em diálogos democráticos sobre temas cotidianos e vividos como significativos.

Nossos questionamentos se amparam na curiosidade em saber de que maneira estas/es jovens são incluídas/ os nestas ações, tanto pela maneira como são convidadas/os a participar, seja pelos modos mais pontuais como facilitadoras/es de grupos demonstram interesse pelas opiniões das/os adolescentes. Nossa intenção é refletir sobre como a proposição de grupo com adolescentes de forma mais inclusiva, baseada no diálogo aberto e não julgador, e que busque posicionar os adolescentes como protagonistas das práticas cuja temática envolva sua própria sexualidade, influencia na participação destas/es adolescentes, que pode se revelar, dentre outras maneiras, na forma como apresentam suas opiniões ao longo do processo grupal.

Cientes de que o termo "práticas colaborativas" tem sido adotado de forma ampla na literatura, remetendo a diferentes significados e orientações práticas, neste estudo adotamos as proposições de Harlene Anderson (2017), para quem a ideia de colaboração remete a uma postura filosófica que implica em transformações da maneira de ser e estar com as pessoas. A reflexão que a autora adota é sensível às transformações no mundo, globalização, internet e descrença nas instituições democráticas rígidas que influenciam as relações de maneira ampla, especificamente, neste caso, na relação entre profissionais e clientes. Ela indica que muitas dessas relações não apenas ignoram a humanidade, como a violam.

Com base nesse entendimento, a autora apresenta um guia conceitual que pode sensibilizar práticas, dando ênfase à importância de conversar com as pessoas de maneira apreciativa e reconhecê-las como um ser humano único, e não como pertencentes a categorias de pessoas, e que suas vozes valem a pena ser ouvidas (Anderson, 2017). Em resumo, a postura filosófica adotada busca auxiliar os/as profissionais a refletirem sobre como podem promover relacionamentos colaborativos e conversas dialógicas (Anderson, 2016). A relação com essas ideias, bem como com as pesquisas descritas nesta seção, serviram como inspiração para a apresentação, planejamento, desenvolvimento e descrição da pesquisa que deu origem ao presente artigo.

De acordo Harlene Anderson (2017), as práticas colaborativas partem de pressupostos dialógicos, os quais dizem respeito a (a) manter o ceticismo, ou seja, posicionar-se de forma crítica e questionadora sobre o conhecimento entendido como verdade universal; (b) evitar generalizações, o que significa não criar categorias definidoras de ações, pois se corre o risco de não entender as pessoas nas suas singularidades; e (c) privilegiar o conhecimento local, o que garante o entendimento de que as pessoas sabem mais sobre elas mesmas (como seus hábitos, verdades, valores etc.) que qualquer outra pessoa.

Há outras maneiras, contudo, de compreender o que são "práticas colaborativas" na literatura, distintas da maneira como adotamos. A expressão muitas vezes é tomada como dada,

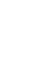


sem preceder discussão. Nosso posicionamento construcionista social, no entanto, nos faz refletir sobre como de diferentes conceitos emergem diferentes práticas, portanto, nos importa discutir quais práticas têm sido visibilizadas pelos diferentes conceitos.

Observamos, por meio de estudo da literatura, que o termo "práticas colaborativas" tem seu entendimento mais difundido implica práticas interdisciplinares ou intersetoriais, visando ao desenvolvimento de ações com adolescentes, entendendo que a eficácia das ações se dá justamente pela colaboração entre os saberes (Morgan, Pullon, Garrett, \& McKinlay, 2019; Peterson, McIntyre, \& Glaés-Coutts, 2018; Prelock, Potvin, \& Savard, 2017; Thielking, Skues, \& Le, 2018). Por outro lado, há também outras pesquisas que descrevem práticas cujo planejamento e desenvolvimento contam com o envolvimento de outras pessoas, para além das/os profissionais e/ou pesquisadoras/es (Gallagher, Murphy, Conway, \& Perry, 2019; Lion, 2017; Ness, Borg, Semb, \& Karlsson, 2019; Ness, Borg, Semb, \& Topor, 2016; Ness, Kvello, Borg, Semb, \& Davidson, 2017; Vianna \& Stetsenko, 2011).

Assim, percebemos dois movimentos distintos na literatura: enquanto um grupo de autoras/es entende práticas colaborativas como a colaboração entre profissionais, outras/os iluminam aspectos que ultrapassam enfoques disciplinares, com destaque ao processo de horizontalização, baseado no diálogo aberto para construções junto com as pessoas com quem se atua.

$\mathrm{O}$ que estas últimas pesquisas demonstram é que colaboração envolve respeito, compaixão, foco em pertencimento, celebração da diversidade, profissionais envolvidas/os e disponíveis a compreender que as pessoas devem viver e ser entendidas na sua diversidade, com suas vidas e necessidades distintas. Para tanto, as/os autoras/es destes trabalhos desencorajam práticas interventivas baseadas em métodos, técnicas e receitas feitos para indivíduos "genéricos". Adicionalmente, é tido como princípio a ideia de que saúde, proteção e promoção de direito das pessoas são responsabilidades da sociedade como um todo.

Assim são incentivadas práticas éticas e específicas de cuidado, nas quais as/os participantes sejam tratadas/os como singulares, não como pertencentes a um grupo específico reconhecido pelo que lhes falta, mas pelos seus potenciais e capacidades. É incentivada postura baseada em ética relacional, responsiva e sensível ao contexto e necessidades de participantes, ao invés de seguir métodos prontos, de forma rígida e inflexível. Ademais, tais pesquisas apontam que a maneira como profissionais estão engajadas/os em ajudar impacta no investimento em estabelecer relacionamentos colaborativos, evitando o jogo de culpabilização, o que contribui para que os serviços alcancem resultados esperados. Percebe-se, então, o caráter necessariamente colaborativo entre a expertise das/os profissionais e a experiência das/os usuárias/ os dos serviços, pessoas estas capazes de construir narrativas sobre suas vidas, baseadas na garantia dos seus direitos humanos (Paiva, 2013).

$\mathrm{Na}$ pesquisa que embasou o presente artigo, os pressupostos de Harlene Anderson (2017) foram guias sensibilizadores que estiveram presentes desde o processo de construção da proposta, ainda em formato de projeto inicial da pesquisa, até cada encontro com as diferentes pessoas que colaboraram para sua realização como um empreendimento relacional. 
Assim, as seguintes orientações de Harlene Anderson (2017) foram inspiradoras para o processo de produção de sentidos:

- Investigação mútua - processo de criação conjunta;

- Expertise relacional - entendimento de que as pessoas são especialistas de si próprias e profissionais são especialistas no espaço e das ações colaborativas;

- Não saber - proposta humilde de saber com o outro ao invés de saber sobre o outro;

- Ser público - compartilhamento dos pensamentos dos profissionais em voz alta;

- Ser espontâneo e viver com a incerteza - fluxo de conversa natural entre as pessoas que guia os caminhos, que são incertos;

- Transformações mútuas - envolvimento ativo de todas as pessoas em processo de influência e transformação; e

- Uma orientação para a vida cotidiana - colaboração e conexão com as pessoas é postura filosófica de igualdade para qualquer relação.

Carla Guanaes (2006) sugere que posição de não saber é central nesta postura filosófica, e refere-se ao engajamento em uma escuta ativa e curiosa, que é possível por perguntas feitas em busca de narrativas diferentes das quais estamos acostumadas a escutar. Esta prática dialógica refere-se à realização de perguntas curiosas, convidando a respostas cujo conteúdo deve ser legitimado e respeitado. Assim, quando sentidos, emergem pelas pessoas em relação, há criação de algo novo, originado do que se tinha com as pessoas previamente, construindo uma nova história. Analogamente, é como a criação de cores, então, quando duas cores primárias se fundem e, em conjunto, criam uma nova cor, que não é mais azul ou amarelo, senão verde. Há processo de transformação evidente não apenas no produto final, mas também no que foi originário.

Assim, o objetivo deste artigo é relatar experiência de intervenção colaborativa como possibilidade para construção de discursos alternativos sobre adolescentes e sexualidades. Nosso interesse é oferecer à literatura a nossa experiência em propor intervenção com adolescentes e profissionais de saúde sobre sexualidade, visando à construção do protagonismo de adolescentes, com ênfase no seu processo colaborativo de construção e proposição do grupo.

\section{MÉTODO}

A experiência aqui relatada é parte de uma pesquisa-ação mais ampla, desenvolvida com base nos pressupostos construcionistas sociais, para fins de construção de tese de doutoramento da primeira autora. Neste artigo, focalizaremos nas experiências vivenciadas pelas autoras em um grupo com adolescentes e profissionais de saúde. A experiência de construção deste grupo é foco de outro texto (Gonzaga \& Guanaes-Lorenzi ${ }^{1}$, no prelo), no qual relatamos detalhadamente os passos envolvidos na construção colaborativa da intervenção.

Seu enquadramento epistemológico é de investigação relacional construcionista social, a partir do qual problematizamos definições estanques e universais, de forma a circunscrevê-las como resultado de um processo de encontros entre pessoas.

\section{Carla Guanaes-Lorenzi}


Então, as relações, tendo a linguagem como ferramenta, são construtoras das noções das múltiplas realidades e verdades (Gergen, 2016). Na pesquisa-ação, mais especificamente, pesquisadoras/es e participantes voltam-se às possibilidades de imaginar o futuro colaborativamente, potencializando o agir conjunto. Desta maneira, transforma-se o posicionamento da/o pesquisadora como a pessoa que "sabe que", para uma pessoa que "sabe com" as outras pessoas envolvidas no fazer pesquisa.

$\mathrm{O}$ projeto ao qual essa pesquisa se vincula foi aprovado por um Comitê de Ética, bem como pelo órgão de saúde do município (CAAE número: 69699317.0.0000.5407). Como medida de proteção às/aos participantes, os nomes apresentados na narrativa a seguir são fictícios, inclusive do município e unidade de saúde. Para as/os participantes, pedimos por sugestões de como gostariam de ser identificados, portanto, suas caracterizações foram indicadas por elas/es. Todas as etapas de construção do grupo e do grupo propriamente dito foram registradas por meio de notas de campo. Além disto, entrevistas iniciais e finais, bem como o grupo com as/os adolescentes e profissionais da USF, foram gravadas em áudio, transcritas posteriormente.

\section{Contexto e território}

A pesquisa se desenvolveu no município Bosque do Cafezal, uma cidade de pequeno porte do interior do Estado de São Paulo. Atuamos especificamente no bairro Bela Vista, onde se localiza a Unidade de Saúde na qual os encontros em grupo com adolescentes e profissionais aconteceram. Participaram desta pesquisa oito adolescentes, com idades entre 12 e 13 anos, com a anuência de seus pais. Participaram também nove profissionais da Unidade Saúde da Família (USF), sendo quatro agentes comunitárias de Saúde (ACS), psicóloga, enfermeira, dois médicos, assistente social e pesquisadoras.

As/os profissionais foram convidadas/os a participar da atividade em reunião de equipe, em um dos passos de construção da intervenção. As pesquisadoras referidas no texto são as duas autoras deste artigo e mais duas pesquisadoras do mesmo grupo de pesquisa, uma de iniciação científica e outra de mestrado, que atuaram como auxiliares de pesquisa.

A pesquisa constitui-se no desenvolvimento de uma intervenção separada em sete etapas, divididas em dois momentos: (a) construção da intervenção - etapa referente ao desenvolvimento de ações junto à unidade e comunidade, visando ao planejamento e à construção colaborativa do grupo; e (b) grupo propriamente dito. $\mathrm{O}$ primeiro momento iniciou em setembro de 2017 e finalizou em abril de 2018 , quando a proposta do grupo propriamente dito foi finalmente construída e pôde ser desenvolvida.

Como descrevemos em Gonzaga e Guanaes-Lorenzi, para sua construção foram criados passos em conjunto, trabalhados de maneira pragmática com as/os profissionais da Unidade Bela Vista e as/os adolescentes. O primeiro passo denominou-se "Cotidiano: conhecendo a Unidade Bela Vista", e refere-se ao momento de conhecer Bosque do Cafezal, a Secretaria de Saúde do município, junto às gestoras das diferentes unidades de saúde. A principal atividade deste passo foi decidir conjuntamente sobre a relevância de trabalhar com sexualidade de adolescentes e se havia 
algum contexto da cidade mais adequado para tal. O passo dois, "Construção: articulando redes e saberes", teve como ponto principal chegar à Unidade Bela Vista, conhecer suas profissionais, logística e demandas. Além disto, teve como objetivo refletir sobre possíveis formas de atuação com adolescentes com base no que já havia sido realizado previamente por elas e por outros setores da comunidade, como educação e serviço social.

Os dois primeiros passos foram fundamentais para o seguimento da pesquisa e exigiram que estivéssemos atentas aos processos relacionais, dinâmicas de poder e aspectos políticos para seu desenvolvimento. A condição de doutoranda em psicologia de uma universidade pública no estado de São Paulo poderia previamente fazer emergir entendimentos sobre a primeira autora que não eram compatíveis com as práticas colaborativas. Desta maneira, a sensibilidade, para ser espontânea, humilde e colaborativa com as/os profissionais, possibilitou que, de maneira conjunta, se construísse o grupo com adolescentes. Deveria ser considerado amplamente o contexto político, permeado por movimento de impedimentos e obstáculos colocados por parte de políticos religiosos fundamentalistas, sobre a temática de sexualidade e gênero com adolescentes no Brasil.

Após conhecer o que já havia sido feito e pensar conjuntamente em como propor uma nova ação, o passo três, "Valsinha: convidando adolescentes", teve como principal ação a eleição de como iríamos convidar adolescentes a estarem nos encontros na Unidade Bela Vista. Estas decisões foram tomadas em conjunto, baseadas nas demandas e cuidados vividos pelas profissionais da unidade. Após realizados os convites e recebidas as referidas anuências das pessoas responsáveis, passamos pelo quarto passo, "Olhos nos olhos: entrevistando adolescentes".

Nas entrevistas iniciais individuais, fomos orientadas por um roteiro semiestruturado elaborado por nós, com perguntas que visaram a investigação de (a) experiências prévias de participação em grupo e maneiras de participação (exemplo: você pode me contar alguma experiência que tenha sido significativa pra você?); (b) modos mais comuns e confortáveis, a fim de favorecer a comunicação verbal no grupo (ex.: quando você está em uma conversa em grupo, com outras pessoas, como você costuma participar dessa conversa?); (c) expectativas quanto aos temas a serem abordados neste grupo (ex.: quais assuntos você acha que seriam interessantes de se abordar? E quais assuntos você gostaria que não fossem abordados?); (d) avaliação da entrevista (ex.: ao final dessa conversa, como você se sente em relação à proposta do grupo?).

Entendemos que a proposição de preparar o grupo colaborativamente foi capaz de demonstrar às/aos adolescentes sua condição imprescindível neste processo, além de ser coerente com a filosofia colaborativa construcionista social. Queríamos aprender com elas/es como nos relacionar com elas/es nos momentos de interação do grupo, e escutar suas demandas a respeito de temáticas e de maneiras de trabalhá-las. Ademais, gostaríamos de saber como propor a temática da sexualidade na adolescência, de forma a resolver no campo questões políticas ditas impraticáveis.

O último passo de construção desta intervenção foi denominado "Trocando em miúdos: coconstruindo a intervenção" e refere-se aos momentos em que estivemos juntas com profissionais e com adolescentes para 
pensar na organização do grupo propriamente dito. Com as/os profissionais o processo de construção como um todo envolveu chamá-las/os para reuniões de equipe, com a proposta de tomar decisões compartilhadas. Tal ação favoreceu que diferentes saberes estivessem juntos, em dinâmica diferente do que estavam habituadas/os, para pensarmos e decidirmos quais seriam as deliberações. Estes momentos foram importantes e desafiadores para lidar com dinâmicas de poder entre as profissões (médicos e agentes comunitárias de saúde, por exemplo) e também de gênero (p.e. médico homem e enfermeira gestora mulher).

Com as/os adolescentes, apresentamos os resumos das elaborações trazidas nas entrevistas individuais, no que se refere às temáticas elencadas, e também levantamos juntas/ os como o grupo poderia funcionar da melhor maneira para todas/os. $\mathrm{O}$ resultado deste encontro foi um "contrato" construído conjuntamente, com orientações de como o grupo poderia funcionar de modo confortável para todas/os. Decidimos que sua estrutura se daria em sete encontros, os quais tiveram duração média de uma hora e meia.

A postura filosófica das práticas colaborativas esteve presente no processo de construção do grupo, que viabilizou sua realização (isto é, o grupo propriamente dito). Durante todo o processo, nossa reflexão foi buscar responder como convidamos a expertise de todas/os. Com profissionais e adolescentes, nos esforçamos para atuar na condição do não saber, proporcionando a emergência da $\boldsymbol{e x}$ pertise relacional e a investigação mútua. Isto quer dizer que trabalhamos conjuntamente para a criação de conhecimentos relacionais e originais daqueles encontros e contexto.

\section{Materiais utilizados}

Após vividos os passos de construção do grupo propriamente dito, já havíamos decidido temáticas e maneiras de atuar com o grupo. No que diz respeito ao desenho de ações dentro dos serviços de saúde, as características das práticas colaborativas são desafiadoras. Acreditamos que trabalhar de forma comprometida é proporcionar momentos de criatividade e descontração, saindo da lógica informativa e sensacionalista.

Desta maneira, para nossa prática, elegemos atividades tanto por endossarmos produções já existentes (provenientes da UNESCO e Ministério da Saúde), como pelo caráter lúdico e crítico que ofereciam. As dinâmicas foram inspiradas e adequadas a partir dos materiais online da Revista Adolescer, no capítulo Dinâmicas de Sexualidade, do Manual do Multiplicador (Ministério da Saúde, 2002) e da cartilha Cá Entre Nós (Unesco, 2012). Especialmente no que se refere às histórias e anedotas, adaptamos o conteúdo para acomodá-las ao contexto.

Encontramos nesta alternativa solução específica para nossas necessidades, ou seja, o material proposto por estas instituições traz critérios científicos e sociais que nos são relevantes. Ao mesmo tempo, nosso interesse em não apenas reproduzir conteúdo, mas situá-lo com responsabilidade ao contexto fez com que as/os participantes percebessem a relação guardada com o cotidiano delas/es. Verificamos essa relação quando elas/es proferiram frases relativas à coerência das situações das anedotas com a vida delas/es. Tais momentos ofereceram para nós a satisfação de perceber tanto que estes materiais são pertinentes para vivências de adolescentes brasileiras/os, quanto a pertinência da adequação e 
construção colaborativa para os contextos específicos.

Um dos desafios encontrados foi eleger atividades que poderiam compor o quadro de temas, sem reproduzir informações baseadas em medo e culpabilização sobre sexualidade e gênero. A partir dos pressupostos das práticas colaborativas, tínhamos, acima de tudo, o interesse de sair da condição de especialista e buscar por formas de participação que proporcionassem a construção de sentidos de maneira conjunta. Para ilustrar esta constatação, exemplificamos com algumas das atividades que trabalhamos, de acordo com os temas:

- Gêneros e sexualidade (participação das ACS Lisa e Manoela): debate em grupo sobre anedotas criadas, exemplo: Davi quer comprar uma boneca para seu irmãozinho de 3 anos. Ele já viu algumas muito bonitas na loja. Mas, quando comenta isso com seu amigo Matheus, este responde: "Meninos não brincam com bonecas". O que Davi deve fazer?

- Puberdade (participação das ACS Lisa e Manoela, psicóloga Ana Liz): Escutar a música Não vou me adaptar, de autoria de Nando Reis, e conversar sobre o grande tema: $O$ que é ser adolescente hoje $e$ as possibilidades da adolescência.

- Métodos contraceptivos (participação da enfermeira Carolina, médico Carlos e ACS Lisa e Manoela): Apresentação do vídeo Campanha Ana (projeto Faça Bonito). Apresentação dos métodos contraceptivos distribuídos no SUS, seu uso e funcionamento.

- Sexualidade na adolescência (participação das ACS Lisa e Manoela): Filme As Melhores Coisas do Mundo. Discussão sobre vivências da sexualidade na adolescência e algumas temáticas envolvidas, tais como relacionamentos LGBT, suicídio e bullying.

- Parentalidade e maternidade na adolescência (participação das ACS Lisa e Manoela): Adolescentes cuidaram por uma semana de um pintinho (entregue na semana anterior). Debate sobre o cuidar/ser responsável. Finalização com teatro sobre um relacionamento heterossexual entre adolescentes, a iniciação da vida sexual, possibilidade de gravidez e impactos.

- Álcool e outras drogas (participação da psicóloga Ana Liz e ACS Lisa e Manoela): Apresentação do vídeo Nuggets para discussão sobre o que é uso e abuso de substâncias.

- Escolhas e repercussões futuras: debate sobre anedotas em grupo e compartilhamento no grupo maior. Exemplo: Eu estou namorando há dois meses com a Lívia e ainda estamos nos conhecendo. Sempre tive planos pra um futuro próximo, como entrar na faculdade ou começar a trabalhar. Pensando nisso, percebi que Livia nunca havia compartilhado algum plano dela comigo. Quando fomos conversar, Lívia acabou confessando que não consegue fazer planos porque seu pai faz uso abusivo de álcool e, com frequência, é violento com ela e sua mãe. Por conta desse medo, Lívia não pensa em deixá-la sozinha. Eu gostaria de ajudar Livia e sua mãe, mas não sei o que fazer. 
Antes dos encontros, enviávamos mensagens virtuais às/aos participantes lembrando que nosso encontro estava chegando. Por esta via também negociamos horários, atrasos, enviamos materiais utilizados e destacávamos eventuais lembranças. Solicitávamos que o recado pudesse ser passado às/aos que não tinham o aplicativo e/ou celular, e, por isto, não participavam do grupo virtual. Também foi pelo grupo virtual que o grupo de adolescentes recebeu o nome Geração Jovem. A iniciativa deste recurso partiu de uma das adolescentes, que também ficou responsável por criá-lo, agregar membros e nomeá-lo. Entendemos que este recurso foi importante para adesão e relação com o grupo, reforçando seu espaço metafórico.

Desta forma, entendemos que as práticas colaborativas permitem às/ aos profissionais buscarem passar da posição do especialista que sabe a única verdade que será transmitida à/ao usuária/o do serviço, para a legitimação de que estas últimas sejam também entendidas como especialistas de sua própria história. Keneth Gergen e Ottar Ness (2016), ao citarem Lynn Hoffman (1993, p. 4), sugerem que questionar "a estrutura top-down" presente no campo médico não é tarefa fácil, pois desafia séculos de uma prática tradicionalmente legitimada na cultura ocidental.

Assim, nosso caminho de construção de sentido buscou dar visibilidade ao que foi gerado nas pesquisadoras em contato com o grupo, destacando potencialidades e desafios, sentimentos e impressões do envolvimento nos encontros de grupo. Dessa forma, enfatizamos o que pode ser um modo de participação ativa das pesquisadoras.

\section{RESULTADOS}

Toda pesquisadora tem de ir aonde 0 povo está: narrativa de um processo de pesquisa-ação

Esta narrativa é fruto da inspiração pelas orientações de Harlene Anderson (2017) a respeito de como práticas podem ser desenvolvidas de maneiras colaborativas, e quais influências exercem para o desenvolvimento de um grupo. Nesta pesquisa especificamente, tivemos contato com tais orientações em distintos momentos: em seu planejamento antes de ir a campo; na própria relação com o campo; nas reuniões com as/ os profissionais; nos convites às/aos adolescentes; na proposição do grupo com as/os adolescentes e profissionais e, posteriormente, na escuta dos áudios e na escrita deste material.

Em cada fase do desenvolvimento desta pesquisa, em coerência com as práticas colaborativas, fizemos diferentes perguntas que puderam nos mover para sua continuação. Para a relevância deste material, nos perguntávamos como poderíamos convidar as/os adolescentes, de modo que se sentissem respeitadas/os e imprescindíveis para o caminhar destas ações. Considerando as diferenças inerentes a cada uma/um delas/es, como mediar as atividades propostas de maneira a dar conta de promover um espaço dialógico capaz de acolher silêncios e motivar falas, desde que não fossem repetidamente provenientes das mesmas pessoas. Posteriormente, nossos questionamentos foram construídos com base na reflexividade para a produção do texto. Ou seja, após vivenciar o contato em grupo ao vivo, como traduzir o que sentimos e vivemos para um texto acadêmico? 
Portanto, esta análise pretende apresentar impressões que tivemos como pesquisadoras e participantes desta pesquisa durante os encontros realizados com o grupo Geração Jovem. A partir da leitura extensa e criteriosa do material criado, pudemos ter uma visão global das conversas produzidas e, num entendimento do que pode ser a participação ativa das pesquisadoras neste momento, criamos uma narrativa do que foi produzido em nós, considerando sentimentos e impressões sobre o desenvolvimento deste grupo.

Elucidamos, então, três modos de participação de adolescentes distintos no processo grupal, seja pelas suas opiniões, maneiras de se posicionar e também nas relações que estabeleciam entre outras/os participantes do grupo. Também apresentamos nossos próprios desafios em termos de trabalhar a temática e como as relações com profissionais foram ao encontro ou desencontro a tais desafios.

O destaque a estas/es três adolescentes objetiva dar visibilidade para como colocamos em prática as orientações colaborativas. Assim, quando percebemos que estas/es três adolescentes poderiam ser narrados de forma a reproduzir impressões categorizantes ("bagunceiro", "nerd" ou "quietinha”), nos perguntamos de que outra maneira essa história poderia ser feita e contada. Em outras palavras, estas/es três participantes apresentavam maneiras de se relacionar em grupo bastante específicas, seja por serem mais tímidas ou extrovertidas que o restante do grupo. Também por demonstrarem interações que nos surpreenderam em algum determinado momento, por meio de falas ou atuações que diferiam delas/es próprias/os ou do restante do grupo, alimentando outras narrativas possíveis.
Com notoriedade, aparece o Alemão. E não só nesta escrita, mas o Alemão é notado por onde passa. Ele não se deixa desapercebido, tem um perfil de adolescente que é popular na escola e vizinhança, vive na diretoria da escola pelo seu comportamento "inadequado" para o ambiente escolar e não se engaja tanto nas tarefas escolares quanto nas tarefas de entreter as pessoas. Seu estereótipo é de deixar professoras/es atentas/os às suas manifestações, especialmente porque mobiliza grupos com sua facilidade em liderar. Nossos encontros tiveram a sorte de poder ser entretidos pela presença dele, mas, diferente do que acreditamos que seja na escola, nos surpreendemos com a relação que Alemão criou com os temas do nosso grupo. A todo encontro, retomávamos o que foi feito na semana anterior, e ele se recordava de detalhes que as/os demais não lembravam. Quando abríamos o momento para compartilhar opiniões e experiências, podíamos contar com a participação dele de forma bastante sincera, mesmo que suas opiniões fossem divergentes da maioria e, para que ele sentisse que sua participação tinha essa relevância que estamos descrevendo, retornávamos dizendo quão valiosa era sua fala.

De perfil oposto, Sorriso se destaca pela qualidade da sua vida escolar. É um menino tímido, que adora estudar. É reconhecido entre o grupo de amigos por ser o "nerd", como foi chamado muitas vezes em nossos encontros, sendo que, em todos eles, lembrava a hora de terminar o encontro, para poder almoçar a tempo de não chegar atrasado na escola. Nossa surpresa foi o envolvimento de Sorriso em temas que poderiam ser desconfortáveis, e, quando ele poderia não ter se exposto, escolheu justamente o caminho contrário, de participar e falar de si tão 
abertamente. Nas entrevistas finais, Sophia e Giovana, de quem é bastante próximo, destacaram a participação dele, dizendo que ele perdeu a timidez nos nossos encontros.

Por fim, a terceira adolescente, que é Mirela, tem um perfil parecido com o de Sorriso, mas um pouco mais inseguro. Quase não escutamos a voz de Mirela nos áudios, mesmo quando buscávamos por ela, perguntando sua opinião sobre algum assunto, ela não costumava compartilhar o que pensava ou alguma história sobre algum acontecimento que viveu. Diferente dos dois meninos, não vamos dizer que Mirela se comportou de maneira distinta em nosso grupo, mas pequenas ocorrências nos chamaram atenção a ponto de querermos destacar aqui. Duas situações ocorreram na participação em uma das atividades que consideramos mais expositiva dos nossos encontros, a respeito dos métodos contraceptivos, em que Carolina e Carlos (profissionais da unidade) propuseram às/aos adolescentes que colocassem camisinha masculina em uma prótese peniana. Todo o encontro foi manejado de forma informativa, leve e descontraída, criando um clima possível para que quem estivesse mais à vontade se engajasse nessa atividade. Sorriso e Giovana não quiseram, o que não foi motivo para que Mirela deixasse de participar. Ainda, compartilhou depois a memória de uma cena. Quando criança, a bolsa de sua mãe caiu no chão e pacotes de camisinha saíram da bolsa e ela perguntou o que eram, e sua mãe inventou que eram remédios para dor nas costas. Esta cena fez com todos rissem e ainda fez a ACS Manoela se lembrar e compartilhar algo parecido que viveu com sua filha pequena.

Ficamos muito satisfeitas com esse tipo de interação entre as/os adoles- centes e também entre elas/es e as/os profissionais. Os encontros nos surpreendiam de maneiras diferentes, com destaque para a participação de alguma ou algumas pessoas, com um clima favorável às conversas sempre presente. $\mathrm{O}$ convite feito em reunião de equipe às ACS Manoela e Lisa, o que envolveu valorizá-las frente às/ aos demais profissionais, também potencializou a efetividade de sua participação nos encontros e o fortalecimento de vínculo entre as/os adolescentes e elas. No encontro em que conversamos sobre parentalidade/maternidade na adolescência, as duas se engajaram ativamente quando propusemos um teatro em que um casal de adolescentes engravida e pedimos para que fossem encenadas algumas situações criadas espontaneamente. Quando elas perceberam que as/os adolescentes estavam tímidas/ os demais para encarar a atividade proposta, elas se prontificaram a atuar. Além da experiência divertida que foi criada, elas também contribuíram com muita relevância para o debate incitado posteriormente.

Não foi apenas neste momento que percebemos a relação que algumas pessoas da equipe criaram com o grupo. Havia sempre um interesse e preocupação nas falas delas conosco, perguntando como estavam indo os encontros, quando acabaria e se haveria outro depois. Estes investimentos nos deram a sensação de que o grupo estava sendo coordenado por nós, mas era fruto de criação conjunta, pois todas/os tinham responsabilidade e interesse pelo seu fluir. Entendemos também que esta intervenção possibilitou criar uma nova relação entre a unidade, a equipe e as/os adolescentes, que puderam percebê-la como um espaço que produz ações de interesse para elas/es. 
Por fim, acreditamos que um ponto que merece destaque são os discursos a respeito de gênero, sobre viabilidades e impedimentos que as pessoas têm ao serem inseridas em alguma delas. Durante nossos encontros, buscamos problematizar compreensões comuns que se tem a respeito dos papéis de homens e mulheres e, também, possibilidades de as pessoas se encaixarem em outras categorias resistentes à norma heterossexual.

A partir de uma análise baseada na leitura intensa do material produzido, percebemos que, em geral, as meninas do Geração Jovem demonstravam maior abertura do que os meninos, com discursos mais flexíveis em relação às possibilidades de gênero, desde a viabilidade de não haver papéis pré-definidos de homens e mulheres, até a possibilidade de pessoas transitarem por outras categorias de gênero que não estas duas. A maior parte dos meninos do grupo ainda se identificava com os discursos hegemônicos acerca do que são os papéis sociais de homens e de mulheres e, em suas falas, demonstraram mais dificuldades de aceitar outros formatos de sexualidade que não heterossexuais.

Ao mesmo tempo, nos chamou bastante atenção o encontro sobre métodos contraceptivos, desenvolvido com a participação dos profissionais de saúde Carolina e Carlos. Neste encontro, as/os jovens se basearam em discurso moralizante quase que completamente voltado para as meninas, com falas carregadas de preocupação para a menina que não se cuida e, ao não tomar a pílula anticoncepcional direito, engravida ou tem que tomar a pílula do dia seguinte. Mesmo que tenhamos nos esforçado para trazer os meninos para o diálogo, refletindo, por exemplo, sobre a corresponsabilização no caso de gravidez, ainda sentimos que suas falas consideravam que era incumbência apenas das meninas a prevenção da gravidez.

\section{REFLEXÕES DESTE MOMENTO}

A postura filosófica das práticas colaborativas é alimentada coerentemente pelos pressupostos do construcionismo social, especialmente pelo debate metateórico a respeito do processo de construção de sentidos. Desta maneira, entendemos que os sentidos são construídos relacionalmente em comunidades locais, e que eles são expressões negociadas e compartilhadas pelas pessoas no momento interativo (McNamee, 2014). Esta maneira de compreender como se dão as negociações do nosso mundo faz parte de um entendimento epistemológico e ontológico relacional, nos quais nos baseamos.

Este pano de fundo nos oferece entendimentos críticos a respeito da construção relacional da sexualidade, especialmente o debate a respeito das questões de gênero. Judith Lorber (2008) propõe que gênero é um princípio organizacional de ordens sociais que divide as pessoas (mais unanimemente entre homens e mulheres) que, ao serem esperadas diferentes, são tratadas diferentes, então se tornam diferentes. Esta maneira de entender gênero é alocada historicamente e interculturalmente, apresentando as diferenças de gênero por lentes de processos sociais e diferenças de hierarquias de poder entre as pessoas.

Circunscrevemos gênero como parte de um processo de construção social, na qual estamos todas/os envolvidas/os, muitas vezes de maneira não percebida, uma vez que somos "genderizados" por sólidas estruturas de poder. Retiramos então o caráter 
puramente biológico de explicações que diferenciam homens e mulheres, de forma a entender estruturas sociais em constante reprodução e manutenção dos sentidos a respeito das diferenças de gênero.

Considerar tais aspectos em nossa intervenção significou atuar de forma ética e comprometida com a produção de novos formatos de realidade, que destoam dos discursos hegemônicos. Atuar colaborativamente com adolescentes e profissionais de saúde de forma a refletir sobre outras formas possíveis de viver sexualidade ou fazer gênero parece ter potencial para a desconstrução de estigmas, rótulos e reprodução de entendimentos estreitos. Concordamos com a afirmação de Murilo Moscheta, Jucely dos Santos, Sheila McNamee e Manoel dos Santos (2014): "acreditamos que uma aproximação dialógica do tema da educação sexual pode gerar um contexto apreciativo e respeitoso; um contexto que permita a coexistência de diversas visões acerca da sexualidade" (p. 277).

Neste texto apontamos um exemplo de como nós atuamos, com desafios e potencialidades exclusivos de nossa experiência e contexto, os quais podem vir a servir como incentivos a leitoras/es interessadas/os em criar ações colaborativas. Percebemos que o esforço em proporcionar espaços dialógicos pode favorecer que as pessoas se sintam convidadas a atuar de uma maneira diferente do que estão habituadas. Especialmente em construir narrativas positivas, que se distanciam de rótulos deficitários.

Essa posição caminha em favor da desconstrução de imagens subjetivas, muitas vezes rotulantes, que podem ser criadas no decorrer da vida em distintos momentos. Neste pequeno fragmento narrativo pudemos acompanhar as mudanças nas posições do
"Alemão-que-causa-problemas", do "Sorriso-tímido-nerd" e da "Mirela-que-não-fala”, para posições bastante ativas, positivas e propositivas para o caminhar do grupo, surpreendendo amigas mais próximas, inclusive.

Da mesma maneira, a relação das profissionais do grupo pode ser capaz de, em contato mais próximo com estas/es adolescentes, endossar outra imagem da adolescência de forma genericamente desinteressada e revoltada, para um grupo de adolescentes com características atuantes, comprometidas e responsáveis. Este grupo foi composto por participantes que elegeram os temas dos encontros, participaram ativamente das atividades, implicaram-se emocionalmente nas tarefas e respeitosamente com as/os demais.

Estas considerações são reforçadas pelas pesquisas encontradas na literatura, que apontam os ganhos das práticas colaborativas pautadas e possibilitadas pelo diálogo aberto e não julgador (Anderson, 2017; Davidson, 2015; Ness et al., 2019, 2016). Nossas práticas, orientadas pela sensibilidade em construir uma intervenção com adolescentes e profissionais (ao invés de para elas/es); a proposição das entrevistas preparatórias de grupo, com perguntas específicas para aprender com elas/es a como mediar esses encontros; a possibilidade de criar orientações para conviver nesses espaços coletivos; bem como elencar quais temáticas trabalharíamos conjuntamente foram algumas das proposições colaborativas que apoiamos para favorecer nossos encontros.

Por fim, entendemos que resistimos aos discursos hegemônicos da falta e da falha quando nos propomos a trabalhar sobre sexualidade e gênero com adolescentes e profissionais em espaços de saúde coletiva. Especialmente, se faz pelo caráter propositivo 
e positivo das práticas colaborativas, pela investigação psicológica relacional, realocando posicionamentos. Então, apresentamos uma possibilidade de intervenção sobre sexualidades e gêneros com adolescentes, filiada à emergência de discursos plurais sobre adolescentes e sexualidades, em marcado momento histórico de ações covardes de apagamento de processos de ensinamento sobre sexualidade e qualquer nuance de diversidade.

\section{REFERÊNCIAS}

Anderson, H. (2016). Algumas considerações sobre o convite ao diálogo. Nova Perspectiva Sistêmica, 25(56), 49-54. Recuperado de http://www. revistanps.com.br/nps/article/ view/240/252

Anderson, H. (2017). A postura filosófica: o coração e a alma da prática colaborativa. In M. Grandesso (Org.), Práticas colaborativas e dialógicas em distintos contextos e populações (pp. 21-34). Curitiba: CRV.

Davidson, A.-L. (2015). A collaborative action research about making self-advocacy videos with people with intellectual disabilities. Social Inclusion, 3(6), 16-28.

Gallagher, A. L., Murphy, C., Conway, $P_{n}$ F., \& Perry, A. (2019). Engaging multiple stakeholders to improve speech and language therapy services in schools: an appreciative inquiry-based study. BMC Health Services Research, 19(1), 216-226. https:// doi.org/10.1186/s12913-019-4051-z

Gergen, K. J. (2016). Toward a visionary psychology. Humanistic Psychologist, 44(1), 3-17. https://doi. org/10.1037/hum0000013

Gergen, K. J. \& Ness, O. (2016). Therapeutic Practice as Social Construction. In The Palgrave Han- dbook of Adult Mental Health (pp. 502-519). London: Palgrave Macmillan UK. https://doi. org/10.1057/9781137496850_26

Guanaes, C. (2006). A construção da mudança em Terapia de Grupo. São Paulo: Vetor.

Lion, C. M. (2017). Caminhando no Contexto das Práticas Colaborativas e Narrativas: experiências profissionais transformadas. Nova Perspectiva Sistêmica, 26(57), 2136. Recuperado de http://www. revistanps.com.br/nps/article/ view/275/267

Lorber, J. (2008). Constructing Gender: The Dancer and the Dance. In Handbook of Constructionist research (pp. 531-544). New York: Guilford Press.

McNamee, S. (2014). Construindo conhecimento/construindo investigação: coordenando mundos de pesquisa. In C. Guanaes-Lorenzi, M. S. Moscheta, C. Corradi-Webster, \& L. V. Souza (Orgs.), Construcionismo social: discurso, prática e produção de conhecimento. (pp. 105-131). Rio de Janeiro: Instituto Noos.

Ministério da Saúde. (2002). Manual do Aplicador: Adolescente. Brasília, DF: Autor.

Morgan, S., Pullon, S., Garrett, S., \& McKinlay, E. (2019). Interagency collaborative care for young people with complex needs: Front-line staff perspectives. Health \& Social Care in the Community, 27(4), 1019-1030. https://doi.org/10.1111/ hsc. 12719

Moscheta, M. S. Santos, J. C., McNamee, S., \& Santos, M. A. (2014). Diálogo e transformação: estratégias para o trabalho com a diversidade sexual no contexto educacional. In C. Guanaes-Lorenzi, M. S. Moscheta, C. Corradi-Webster, \& L. V. Souza (Orgs.), Construcionismo so-
1 Gonzaga, D. \& Guanaes-Lorenzi (no prelo). Colaboração com Profissionais ce Saúde como Princípio para Desenvolvimento de Ação com Adolescentes. In M. Grandesso (Org.), Construcionismo social e práticas colaborativo-dialógicas: contextos de ações transformadoras. Curitiba: CRV. 
cial: discurso, prática e produção de conhecimento. (pp. 137-153). Rio de Janeiro: Editora Noos.

Ness, 0., Borg, Man, Semb, R., \& Karlsson, B. (2019). "caminhando lado a lado": práticas colaborativas nos tratamentos de saúde mental e uso de substâncias. Nova Perspectiva Sistêmica, 27(61), 6-21. Recuperado de http://www.revistanps.com.br/ nps/article/view/409/329

Ness, 0., Borg, M., Semb, R., \& Topor, A. (2016). "Negotiating partnerships:" parents' experiences of collaboration in community mental health and substance use services. Advances in Dual Diagnosis, 9(4), 130-138. https://doi.org/10.1108/ ADD-04-2016-0010

Ness, 0., Kvello, Ø., Borg, M., Semb, R., \& Davidson, L. (2017). "Sorting things out together": Young adults' experiences of collaborative practices in mental health and substance use care. American Journal of Psychiatric Rehabilitation, 20(2), 126-142. https://doi.org/10.1080/15487768.2 017.1302369

Paiva, V. S. F. (2013). Psicologia na saúde: sociopsicológica ou psicossocial? Inovações do campo no contexto da resposta brasileira à aids. Temas em Psicologia, 21, 531-549. https://doi. org/10.9788/tp2013.3-ee00-pt

Peterson, S. S., McIntyre, L. J., \& Glaés-Coutts, L. (2018). Collaborative action research in Northern Canadian rural and Indigenous schools: learning about young children's oral language in play contexts. Educational Action Research, 26(5), 787-802. https://doi.org/10.1080/09650792.2 017.1402686

Prelock, P. A., Potvin, Ms-Cus, \& Savard, L. (2017). Interprofessional Education and Practice: A Family-Centered Approach to Autism. Semi- nars in speech and language, 38(5), 360-367).

Thielking, M., Skues, J., \& Le, V.-A. (2018). Collaborative Practices Among Australian School Psychologists, Guidance Officers and School Counsellors: Important Lessons for School Psychological Practice. The Educational and Developmental Psychologist, 35(1), 18-35. https://doi.org/10.1017/edp.2018.4

Unesco. (2012). Cá entre nós: guia de educação integral em sexualidade entre jovens. São Paulo: Governo de São Paulo/UNESCO.

Vianna, E. \& Stetsenko, A. (2011). Connecting Learning and Identity Development through a Transformative Activist Stance: Application in Adolescent Development in a Child Welfare Program. Human Development, 54(5), 313-338. https://doi. org $/ 10.1159 / 000331484$

\section{AGRADECIMENTOS À AGÊNCIA DE FOMENTO}

Fundação de Amparo à Pesquisa do Estado de São Paulo - FAPESP, processos $n^{\circ} 2016 / 25882-4$ e 2018/16490-0. 
(http://orcid.org/0000-0001-6465-1011)

de casal pela UNIFESP e mestra em Educação Especial pela UFSCar. Doutoranda no Programa de Pós- Graduação em Psicologia da Faculdade de Filosofia, Ciências e Letras de Ribeirão Preto (FFCLRP-USP), Ribeirão Preto/SP, Brasil.

E-mail: domitila.gonzaga@gmail.com

\section{CARLA GUANAES-LORENZI}

(http://orcid.org/0000-0001-6263-9078) é psicóloga e terapeuta familiar. Mestre e doutora em Psicologia pela Universidade de São Paulo (USP), com estágio de pesquisa na University of New Hampshire (EUA). Professora do Programa de Pós-Graduação em Psicologia da Faculdade de Filosofia, Ciências e Letras de Ribeirão Preto (FFCLRP-USP), Ribeirão Preto/SP, Brasil e Departamento de Psicologia da Faculdade de Filosofia, Ciências e Letras de Ribeirão Preto (FFCLRP-USP), Ribeirão Preto/SP, Brasil. Membro associado do Taos Institute.

E-mail: carlaguanaes@usp.br 